\title{
1,2,3,4-Tetrahydropyrimidine Derivative for Selective and Fast Uptake of Cadmium Ions from Aqueous Solution
}

\author{
Mohamed Ould M'hamed ${ }^{1,2, *}$ and Lotfi Khezami ${ }^{1}$ \\ 1 Department of Chemistry, College of Sciences, Imam Mohammad Ibn Saud Islamic University (IMSIU), \\ Riyadh 11623, Saudi Arabia; lkhezami@gmail.com \\ 2 Unité de Chimie Moléculaire et Environnement (UCME), Département de Chimie, Faculté des Sciences et \\ Techniques, Université de Nouakchott Al Aasriya, (UNA), Nouakchott 880, Mauritania \\ * Correspondence: medabdelwedoud@gmail.com or mamhamed@imamu.edu.sa
}

Received: 14 May 2019; Accepted: 7 June 2019; Published: 10 June 2019

\begin{abstract}
The aim of this work was to evaluate the performance of a 1,2,3,4-tetrahydropyrimidine derivative as a powerful heterocyclic compound for the elimination of $\mathrm{Cd}(\mathrm{II})$ ions from aqueous solutions. The tetrahydropyrimidine derivative was prepared during $30 \mathrm{~min}$ of milling by planetary ball mill with a ball-to-powder mass ratio of 8:1 and a rotation speed of $750 \mathrm{rpm}$. Nuclear magnetic resonance (NMR) and infrared (IR) were used to identify the obtained tetrahydropyrimidine derivatives. Furthermore, batches of experiments were carried out to establish the adsorption equilibrium, kinetics, and thermodynamic variables of the tetrahydropyrimidine derivatives for toxic heavy $\mathrm{Cd}(\mathrm{II})$ ions. The adsorption data were simulated by applying the Langmuir manner, the Freundlich equation, the pseudo-first-order and pseudo-second-order equations. The adsorption procedure was discovered to be very influenced by $\mathrm{PH}$. The removal of heavy metal ions reached a maximum value quickly within $6 \mathrm{~min}$ and the adsorption data better adjusted the Langmuir isotherm than that of the Freundlich isotherm. The maximum Cd(II) ions adsorption capacity was approximated to be $151.16 \mathrm{mg} \mathrm{g}^{-1}$ at $328 \mathrm{~K}$ and a pH of 6 to 7 . It was found that the adsorption kinetics of $\mathrm{Cd}(\mathrm{II})$ ions obeyed pseudo-second-order adsorption kinetics. The examination of the thermodynamic variables of tetrahydropyrimidine derivative showed a spontaneous endothermic adsorption procedure. Otherwise, positive entropy values put forward a rise in the randomness at the solid-solution interface when heavy metal ions are adsorbed.
\end{abstract}

Keywords: 1,2,3,4-tetrahydropyrimidine derivative; ball milling; heavy metal; Cd(II) ion; adsorption; kinetics; thermodynamics

\section{Introduction}

Currently, the global pollution rate is increasing due to many different factors, such as the high heavy metal discharge concentrations from industries. In addition to other toxic heavy metals such as lead and copper, cadmium is a highly toxic heavy metal and is known as one of the most dangerous to human health. In addition, cadmium is not biodegradable, and exposure to this pollutant can lead to various diseases and disorders [1]. The method commonly used to solve these serious environmental problems is adsorption, which has been proven to be one of the most efficient and cost-effective methods for water treatment applications [2]. However, the real problem in this area is the choice of selecting new adsorbents.

Various adsorbents have been applied to remove the ions of heavy metal, such as activated carbon [3], clays [4,5], zeolites [6-8], and agricultural residues [9-12]. Moreover, the major drawbacks of these adsorbents are their low adsorption capacity and their difficulties in separating some of them 
from water. Recently, special attention has been given to the organic-inorganic hybrid polymers and functionalized polymers as attractive absorbents, due to their high efficiency for the removal of heavy metals from contaminated water [13-27]. In these mixtures, the organic compounds are combined with inorganic substrates, which provide a high interaction with selected metal ions and relatively high adsorption capacities of the metal ions. Functionalized and hybrid polymeric materials often exhibit the best properties and exhibit high performance in terms of physical, chemical, and mechanical properties [28].

This research paper focuses on the efficiency and selectivity of the organic heterocyclic compound (1,2,3,4-tetrahydropyrimidine derivative) as a promising adsorbent for the uptake of Cd(II) ions from aqueous solutions. The pyrimidine derivative was prepared by planetary ball mill as a green synthesis technique, and its structure was confirmed by nuclear magnetic resonance (NMR) and infrared (IR). The effects of initial $\mathrm{pH}$, temperature, and initial concentration on $\mathrm{Cd}(\mathrm{II})$ removal were studied. Mathematical models were also investigated, including the Langmuir and Freundlich models for the sorption isotherm data, and the kinetics data (first and second order equations). The rate constants, the adsorption capacities, and the thermodynamic variations $\left(\Delta \mathrm{H}^{0}, \Delta \mathrm{S}^{0}\right.$ and $\left.\Delta \mathrm{G}^{0}\right)$ were also assessed and discussed.

\section{Materials and Methods}

All the organic reagents (benzaldehyde, ethyl acetoacetate, urea) used in this work were purchased from Sigma-Aldrich (St Louis, MO, USA). The ball milling apparatus used in this study was a Planetary Micro Mill PULVERISETTE 7 (Fritsch, Idar-Oberstein, Germany) classic line equipped with tempered steel bowls of $45 \mathrm{~mL}$ and tempered steel grinding balls of $10 \mathrm{~mm}$. The melting point was determined with a Stuart SMP10 melting point equipment (Bibby Scientific Staffordshire, UK). IR spectra were provided by an FT-IR-Tensor 27 spectrometer (Bruker, Ettlingen, Germany) in KBr pellets. ${ }^{1} \mathrm{H}$ and ${ }^{13}$ C-NMR spectra were obtained using a Bruker 400 NMR spectrometer (Bruker Biopsin, Rheinstetten, Germany) in DMSO-d6 with TMS as the internal standard. Chemical shifts were indicated in units of parts per million (ppm).

\subsection{Synthesis of Ethyl 6-Methyl-2-oxo-4-Phenyl-1,2,3,4-Tetrahydropyrimidine-5-Carboxylate (4)}

The 1,2,3,4-tetrahydropyrimidine compound (4) (Figure 1) was synthesized according to the reference [29]. Equimolar amounts of benzaldehyde (1), ethyl acetoacetate (2), and urea (3) were placed into tempered steel vials with tempered steel balls (10 $\mathrm{mm}$ in diameter) in a Planetary Micro Mill Pulverisette 7. The ball-to-reagent weight ratio equals 8:1, and the Planetary Micro Mill was set to $750 \mathrm{rpm}$. The 1,2,3,4-dihydropyrimidine product (4) was obtained in pure form after $30 \mathrm{~min}$ of milling without further purification. The structure of the synthesized product (4) was confirmed by NMR $\left({ }^{1} \mathrm{H}\right.$ and $\left.\left.{ }^{13} \mathrm{C}\right)\right)$ and IR analysis (Figures 2 and 3$)$.

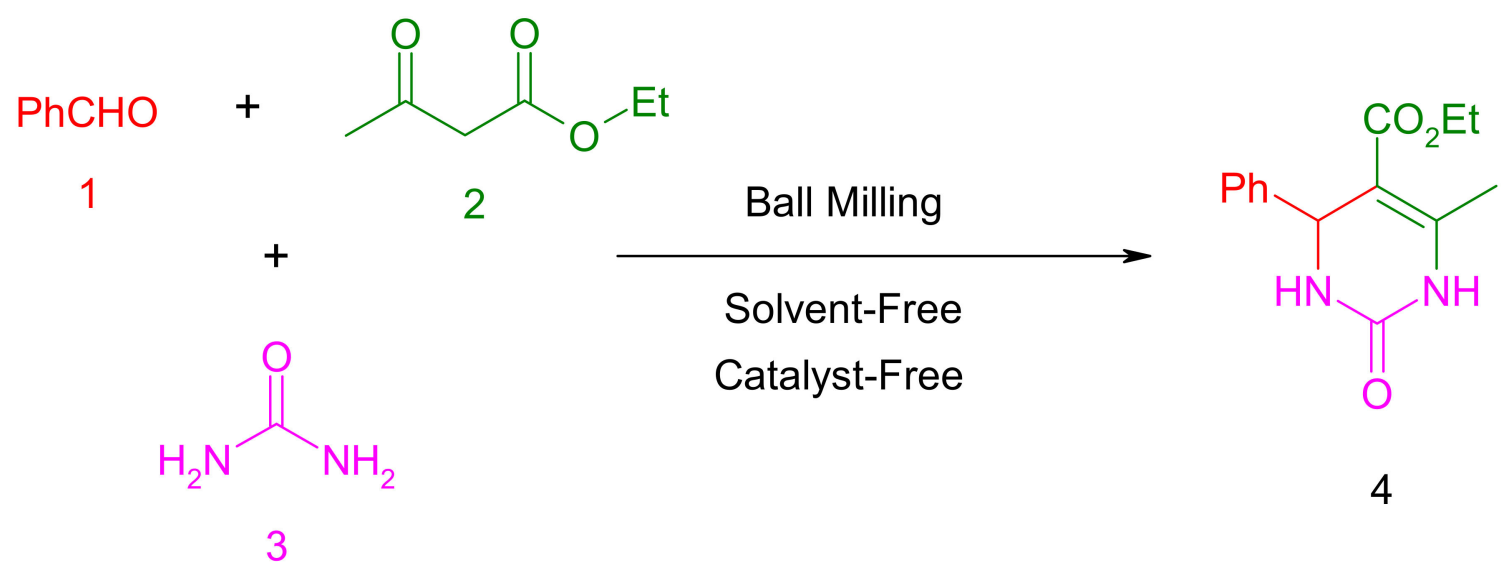

Figure 1. The 1,2,3,4-tetrahydropyrimidine derivative synthesis under ball milling. 


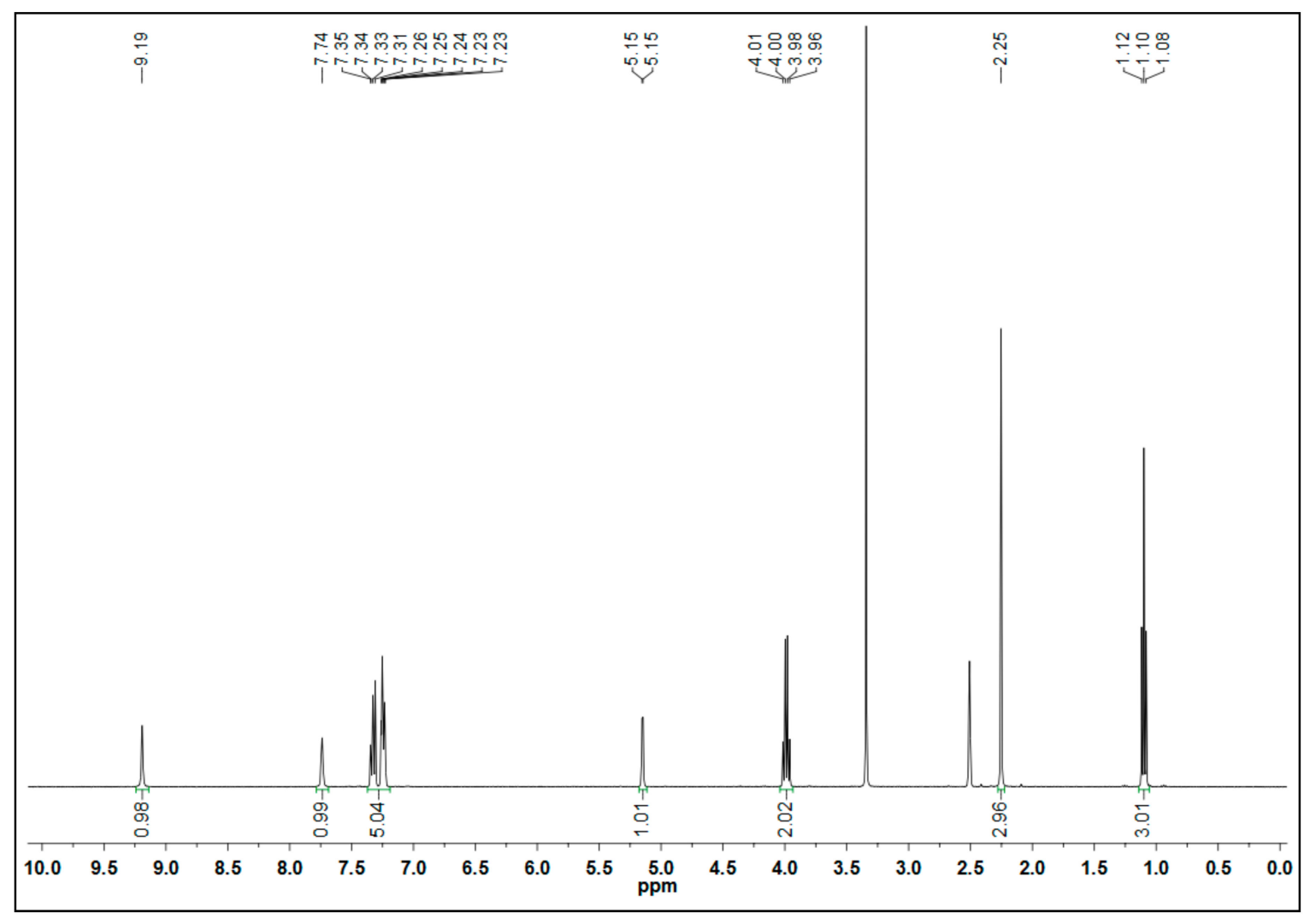

Figure 2. ${ }^{1} \mathrm{H}$-nuclear magnetic resonance (NMR) spectrum of 1,2,3,4-tetrahydropyrimidine derivative 4.

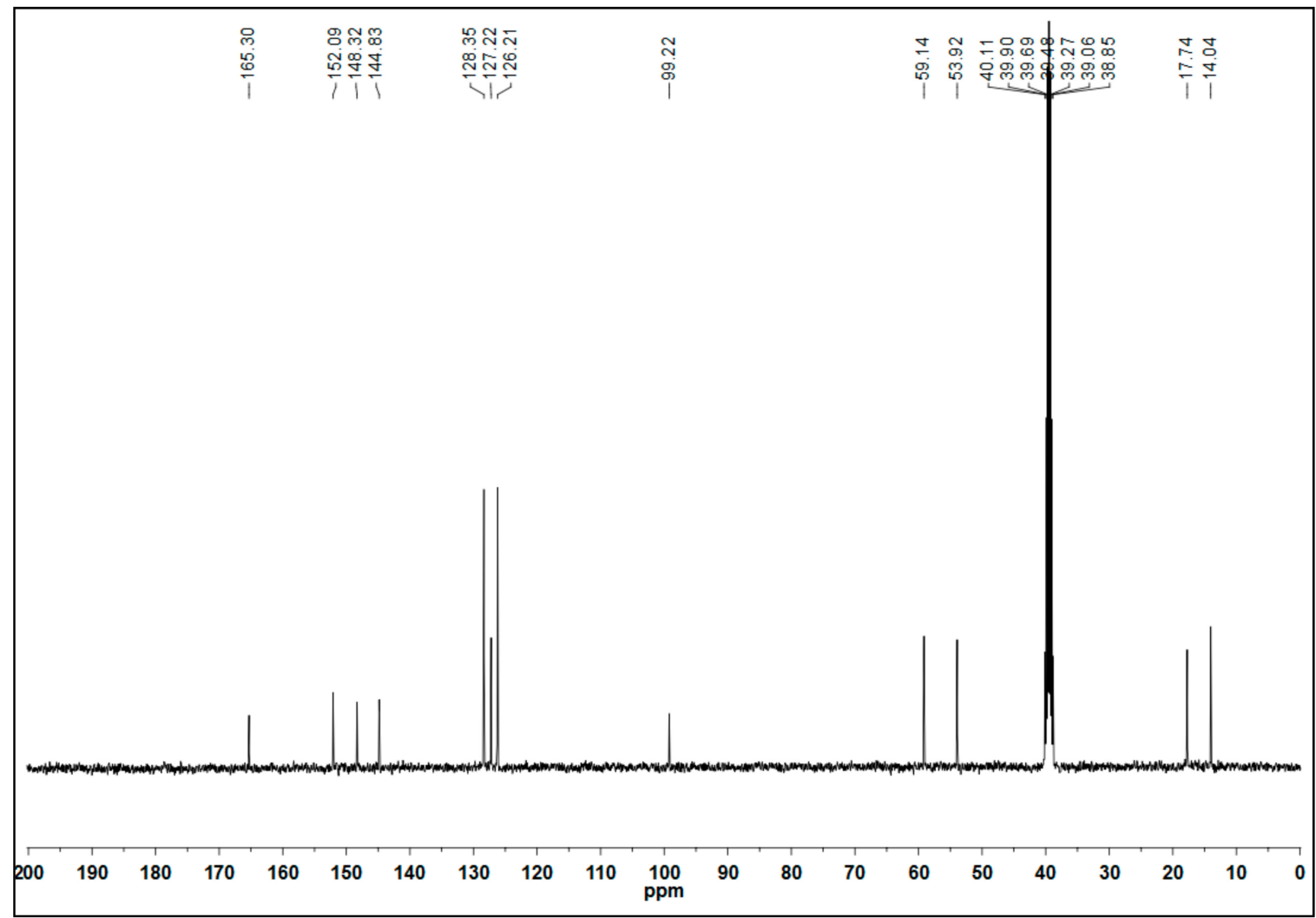

Figure 3. ${ }^{13} \mathrm{C}$-nuclear magnetic resonance (NMR) spectrum of 1,2,3,4-tetrahydropyrimidine derivative 4. 
2.2. Characteristic Data of Ethyl 6-Methyl-2-oxo-4-Phenyl-1,2,3,4-Tetrahydropyrimidine-5-Carboxylate (4)

IR (KBr, vmax, cm $\left.{ }^{-1}\right): 3228,3240.2,3116.8,29781.7,1701.1,1647.1 .{ }^{1} \mathrm{H}-\mathrm{NMR}(400 \mathrm{MHz}, \mathrm{DMSO}-\mathrm{d} 6)$ $\delta 9.19(\mathrm{~s}, 1 \mathrm{H}), 7.74(\mathrm{~s}, 1 \mathrm{H}), 7.37-7.19(\mathrm{~m}, 5 \mathrm{H}), 5.15(\mathrm{~d}, J=3.3 \mathrm{~Hz}, 1 \mathrm{H}), 3.99(\mathrm{q}, J=7.1 \mathrm{~Hz}, 2 \mathrm{H}), 2.28(\mathrm{~s}$, 1H), $1.10(\mathrm{t}, J=7.1 \mathrm{~Hz}, 3 \mathrm{H}) ;{ }^{13} \mathrm{C}-\mathrm{NMR}(100 \mathrm{MHz}, \mathrm{DMSO}-\mathrm{d} 6) \delta 165.30,152.09,148.32,144.83,128.35$, $127.22,126.21,99.22,59.14,53.92,17.74,14.04$.

\subsection{Adsorption Procedure}

\subsubsection{Preparation of Cd(II) Ion Solutions}

The (1000 $\mathrm{mg} \mathrm{L}^{-1}$ ) stock solution of Cd(II) was made by dissolving necessary amounts of cadmium nitrate $\left(\mathrm{Cd}\left(\mathrm{NO}_{3}\right)_{2}\right)$, in distilled water. Experimental solutions at the required concentration were then achieved by successive dilutions. All the reagents were of analytical category, purchased from Sigma-Aldrich (St Louis, MO, USA) and were used as received without further purification [30].

\subsubsection{Analysis of Cd(II) Ion Adsorption}

In order to investigate the adsorption performance of the adsorbent towards Cd(II), many experiments were performed in batch mode by mixing together $10 \mathrm{mg}$ of 1,2,3,4-tetrahydropyrimidine compound (4) and $25 \mathrm{~mL}$ of ionic cadmium solution in a $50 \mathrm{~mL}$ glass vial with a known $\mathrm{pH}$ and temperature. The initial concentration of cadmium ions was between $20-160 \mathrm{mg} \mathrm{L}^{-1}$, the pH values from 3.0 to 10.0, and the temperature from 298 to $318 \mathrm{~K}$. The mixed amounts were stirred continuously with a shaker at $600 \mathrm{rpm}$ for $12 \mathrm{~h}$. A $15 \mathrm{~mL}$ of the suspension was withdrawn from each flask, centrifuged at $6000 \mathrm{rpm}$ for $10 \mathrm{~min}$, and also filtered through $0.45 \mu \mathrm{m}$ cellulose acetate syringe filter. The concentrations of $\mathrm{Cd}$ (II) were analyzed with an atomic emission spectrometry (Spectro genesus ICP-OES). All the experimentation were carried out twice, and the average values are used in this work.

According to Equation (1), the mass (mg) of $\mathrm{Cd}(\mathrm{II})$ removed by $1 \mathrm{~g}$ of the adsorbent, $q_{e}$, is:

$$
q_{e}=\frac{\left(C_{0}-C_{e}\right) \cdot V}{\mathrm{~m}}
$$

where parameter $C_{0}$ represents the liquid phase initial concentration $\left(\mathrm{mg} \mathrm{L}^{-1}\right), C_{e}$ is the cadmium ion aqueous-phase concentration after adsorption $\left(\mathrm{mg} \mathrm{L}^{-1}\right)$, and $\mathrm{V}$ represents the volume of the pollutant solution $(\mathrm{L}), \mathrm{m}$ is the mass of the dihydropyrimidine derivative.

The sorption data of cadmium ions are correlated to the theoretical models of Langmuir and Freundlich:

Langmuir equation

$$
\frac{C_{e}}{q_{e}}=\frac{1}{Q_{0}} C_{e}+\frac{1}{Q_{0} \cdot \mathrm{b}},
$$

Freundlich equation

$$
\operatorname{Ln}\left(q_{e}\right)=\frac{1}{\mathrm{n}} \operatorname{Ln}\left(C_{e}\right)+\operatorname{Ln}(k),
$$

where $C_{e}$ represents the equilibrium concentration of the solute in the solution $\left(\mathrm{mg} \mathrm{L^{-1 }}\right), q_{e}$ is the amount of cadmium ions adsorbed per unit weight of adsorbent $\left(\mathrm{mg} \mathrm{g}^{-1}\right), Q_{0}$ depicts the theoretical monolayer saturation capacity [31], and b accounts for the Langmuir equilibrium constant. The values of $Q_{0}$ and b can be graphically specified from the linearized and rearranged Langmuir expression (Equation (2)). $k$ and $n$ are constants allied to the strength of the adsorption and distribution bonds, respectively [32]. The values of $k$ can be obtained graphically according to Langmuir equation (Equation (3)). The constant $k$ can be defined as an adsorption coefficient which represented the quantity of adsorbed metal ion for a unit equilibrium concentration (i.e., $C_{e}=1$ ). The slope, $1 / n$, is a measure of the sorption intensity or surface heterogeneity [33]. the situation $1 / n<1$ is the most common 
and corresponds to a normal L-type Langmuir isotherm, while $1 / n>1$ is indicative of a cooperative adsorption which involves strong interaction between the molecules of adsorbate [34], which involves strong interactions between the molecules of the adsorbate themselves. The essential characteristics of a Langmuir isotherm can be expressed in terms of a dimensionless separation factor, $R_{L}$, which describes the type of isotherm:

$$
R_{L}=\frac{1}{1+\mathrm{b} \cdot C_{0}}
$$

where $C_{0}$ is the initial adsorbate concentration in the solution. The $R_{L}$ indicates the shape of the isotherms to be either unfavorable $\left(R_{L}>1\right)$, favorable $\left(0<R_{L}<1\right)$, linear $\left(R_{L}=1\right)$, or irreversible $\left(R_{L}=0\right)$. To envisage the adsorption data of $\mathrm{Cd}(\mathrm{II})$ as a function of time, two kinetic examples were suggested and tested: a pseudo-first-order and a pseudo-second order. The first-order method can be expressed linearly as follows:

$$
\operatorname{Ln}\left(q_{e}-q_{t}\right)=\operatorname{Ln}\left(q_{e}\right)-k_{1} \cdot t,
$$

where $q_{e}$ and $q_{t}$ (in $\mathrm{mg} \mathrm{g}^{-1}$ ) represent the amount of $\mathrm{Cd}$ (II) adsorbed at equilibrium and at time $t$ (min), respectively, and $k_{1}\left(\mathrm{~min}^{-1}\right)$ is the rate constant of first-order adsorption. The values of $k_{1}$ and $q_{e}$ are deduced from the slope of the plot of $\operatorname{Ln}\left(q_{e}-q_{t}\right)$ versus $t$, respectively.

The linear form of pseudo-second-order model is expressed as:

$$
\frac{\mathrm{t}}{q_{t}}=\frac{1}{k_{2} \cdot q_{e}^{2}}+\frac{\mathrm{t}}{q_{e}}
$$

where $k_{2}(\mathrm{~g} / \mathrm{mg} \mathrm{min})$ represents the equilibrium rate constant of pseudo second-order adsorption. The plot $t / q t$ versus $t$ should be linear, when the pseudo-second-order models is adequate. The values of $k_{2}$ and $q_{e}$ can be determined from the slope and intercept of the plot, $\mathrm{t}_{1 / 2}$. The half adsorption time is the time intended to absorb half of the maximal amount of $\mathrm{Cd}(\mathrm{II})$ adsorbed at equilibrium. In the case of a pseudo-second-order process, the value of $t_{1 / 2}$ is calculated by the following relationship:

$$
t_{1 / 2}=\frac{1}{k_{2} \cdot q_{e}} .
$$

The thermodynamic functions $\left(\Delta \mathrm{H}^{0}, \Delta \mathrm{S}^{0}\right.$, and $\left.\Delta \mathrm{G}^{0}\right)$ for the adsorption of cadmium ions by dihydropyrimidine derivative were calculated using the subsequent equations:

$$
\begin{aligned}
& \Delta \mathrm{G}^{0}=-R T \operatorname{Ln} k_{a}, \\
& \Delta \mathrm{S}=\frac{\Delta \mathrm{H}^{0}-\Delta \mathrm{G}^{0}}{\mathrm{~T}},
\end{aligned}
$$

where $k_{a}$ was the equilibrium constant of adsorption and was calculated through $k_{a}=Q_{0} \cdot \mathrm{b}$. The enthalpy change $\left(\Delta \mathrm{H}^{0}\right)$ value was obtained through the slope of the linear curve of $\ln K_{a}$ versus the reciprocal temperature $(1 / T)$. The values of Gibbs free-energy change $\left(\Delta G^{0}\right)$ and entropy change $\left(\Delta S^{0}\right)$ were calculated using Equations (8) and (9), respectively.

\section{Results and Discussion}

\subsection{Adsorption of $C d(I I)$ Ions}

\subsubsection{Effect of Initial Cd(II) Ion Concentrations}

To examine the effect of initial Cd(II) ion concentration, different concentrations (20-160 mg L ${ }^{-1}$ ) of $\mathrm{Cd}(\mathrm{II})$ ions were investigated. We found that if the amount of the 1,2,3,4-tetrahydropyrimidine derivative (4) in the solution is equal to $0.6 \mathrm{~g} \mathrm{~L}^{-1}$ and the initial $\mathrm{Cd}(\mathrm{II})$ concentration is $20 \mathrm{mg} \mathrm{L}^{-1}$, then $98 \%$ of the $\mathrm{Cd}$ (II) ions are removed, whereas, if the initial concentration of the $\mathrm{Cd}$ (II) ions is about $160 \mathrm{mg} \mathrm{L}^{-1}$, the amount removed falls to $79 \%$. In addition, when the initial concentration of Cd(II) 
ions ranges from 20 to $160 \mathrm{mg} \mathrm{L}^{-1}$, the amount removed decreases progressively from $98 \%$ to $78 \%$, respectively. Hence, the removal of Cd(II) highly depends on the concentration, especially for a higher initial concentrations. The decrease in removal efficiency may be ascribed to the fact that when the concentration of metal ions is greater, the active sites of adsorbent are surrounded by many more metal ions and, as a result, the active sites will be accommodated [35].

\subsubsection{Effect of $\mathrm{pH}$}

To investigate the effect of $\mathrm{pH}$ on the removal of $\mathrm{Cd}(\mathrm{II})$ ions, many $\mathrm{pH}$ values $(3,4,5,6,7,8,9$, and 10) were studied at a temperature of approximately $298 \pm 1 \mathrm{~K}$ and for $\mathrm{Cd}$ (II) concentrations between 20 and $160 \mathrm{mg} \mathrm{L}^{-1}$. The contact time was set at $12 \mathrm{~h}$ for all experiments. The experimental results are shown in Figure 4. It was found that the adsorption efficacy of $\mathrm{Cd}(\mathrm{II})$ increased with increasing $\mathrm{pH}$ of the solution, and reached the maximum adsorption value at $\mathrm{pH}(6-7)$. Zhu et al. [36] showed similar results for their research work on the adsorption of $\mathrm{Cd}(\mathrm{II})$ and $\mathrm{Pb}(\mathrm{II})$ ions via amine-functionalized cellulose. The low metal sorption at lower $\mathrm{pH}$, may be explained on the basis of active sites being protonated, resulting in a competition between $\mathrm{H}^{+}$and $\mathrm{M}^{2+}$ for occupancy of the binding sites [37]. The uptake of cadmium ions decreases considerably from $\mathrm{pH} 8$ to 9 , which can be justified by the precipitation of $\mathrm{Cd}(\mathrm{II})$ ions in an alkaline medium rich in hydroxide anions $\left(\mathrm{Cd}^{2+}+2 \mathrm{OH}^{-} \rightarrow \mathrm{Cd}(\mathrm{OH})_{2}\right)$ at a $\mathrm{pH}$ between 8 and 10 .

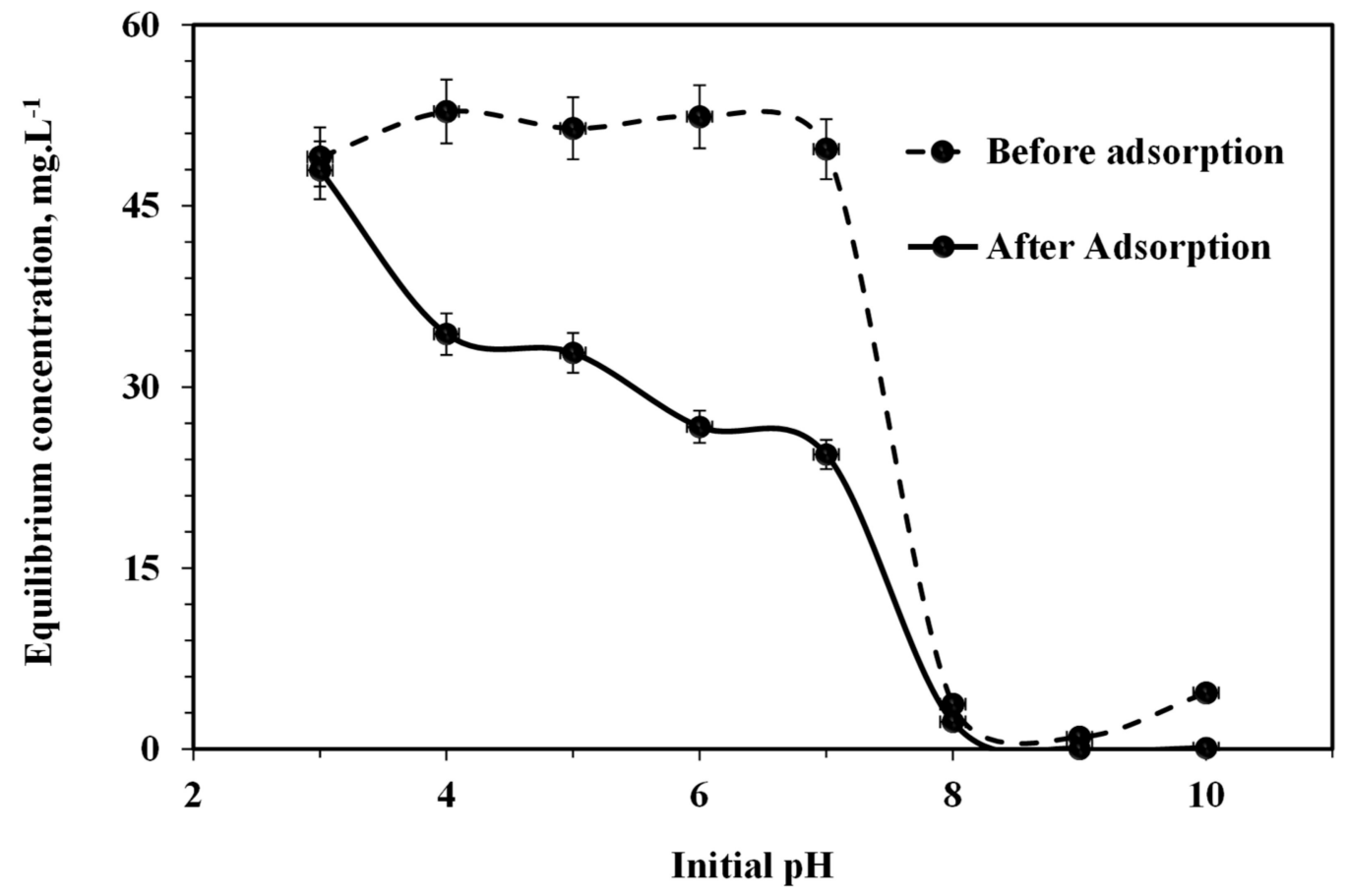

Figure 4. The initial solution $\mathrm{pH}$ effect on the removal of $\mathrm{Cd}$ (II) by 1,2,3,4-tetrahydropyrimidine at room temperature and $C_{0}=52 \mathrm{mg} / \mathrm{L}$ (Dash-line without adsorbent and solid-line with adsorbent).

\subsubsection{Kinetic Study}

The kinetic data of the adsorption of Cd(II) ions as a function of time at $298 \mathrm{~K}$ are illustrated in Figure 5a,b, respectively. It shown in Figure 5a that after a rapid initial increase in adsorption $\mathrm{q}_{\mathrm{t}}$ (about $6 \mathrm{~min}$ ), the equilibrium is reached in almost $40 \mathrm{~min}$. The rapid adsorption of cadmium ions suggests that the heteroatoms $(\mathrm{N}, \mathrm{O})$ in the 1,2,3,4-tetrahydropyrimidine derivative (4) act as donor atoms to rapidly interact with the free $\mathrm{Cd}(\mathrm{II})$ ions present in the solution. Given that the coefficient of magnitude $\mathrm{r}^{2}$ (Table 1) is the one that depends on the validity of the kinetic manners, it should be noted that for a pseudo-first-order model, the correlation coefficient was 0.9405 , indicating a weak correlation, whereas the employment of a pseudo-second-order equation provided a much better correlation coefficient, 
equal to 0.9977 (Table 1). The experimental and calculated values of qe are also very close, as shown in Table 1; thereby, the pseudo-second-order kinetic equation is more appropriate for describing the adsorption kinetics behaviors of $\mathrm{Cd}$ (II) on the 1,2,3,4-tetrahydropyrimidine derivative (4). Zhu and colleagues [36] showed that the pseudo-second-order equation better depicts the sorption kinetics of $\mathrm{Pb}(\mathrm{II})$ and $\mathrm{Cd}(\mathrm{II})$ on amine-functionalized cellulose.
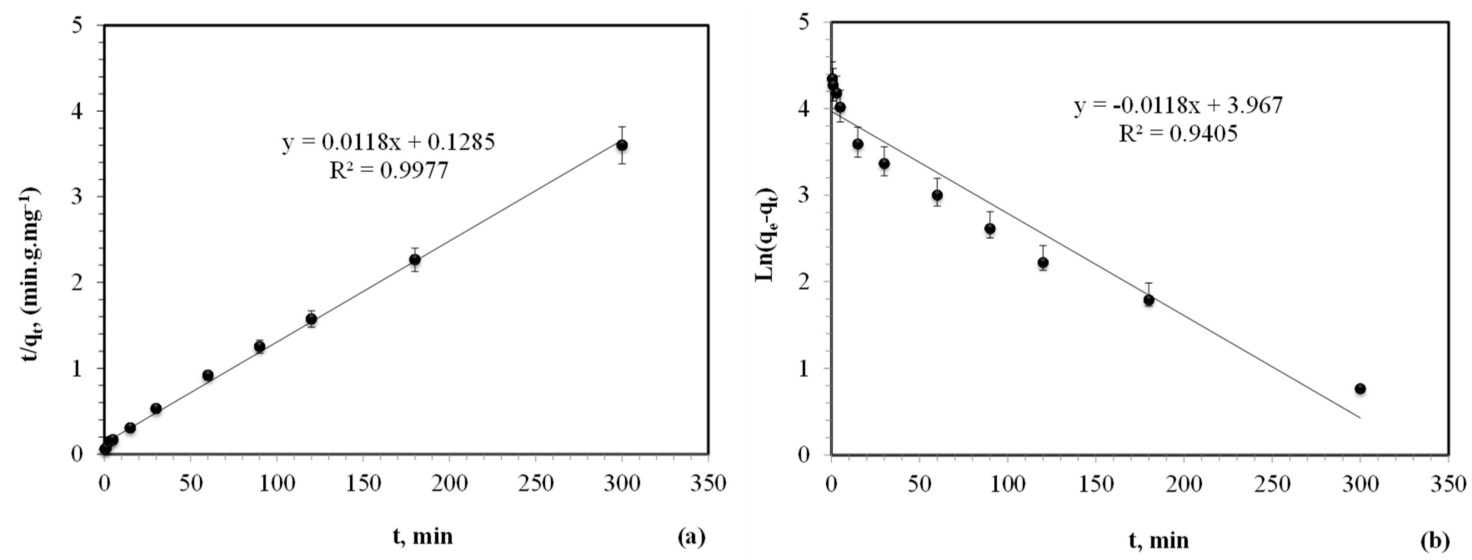

Figure 5. (a) Second-order and (b) first-order kinetic equation for adsorption of Cd(II) on 1,2,3,4tetrahydropyrimidine at $229 \mathrm{~K}$.

Table 1. Rate adsorption coefficients for first and second pseudo-order sorption kinetic models at $298 \mathrm{~K}$, $\mathrm{pH} 7$, and initial concentration $52 \mathrm{mg} \mathrm{L}^{-1}$.

\begin{tabular}{|c|c|c|c|c|c|c|c|}
\hline \multicolumn{2}{|l|}{$t_{1 / 2}$} & \multicolumn{3}{|c|}{ First-Order } & \multicolumn{3}{|c|}{ Second-Order } \\
\hline (s) & $\begin{array}{l}\mathrm{q}_{\mathrm{e}(\exp )}{ }^{\mathrm{a}} \\
\left(\mathrm{mg} \mathrm{g}^{-1}\right)\end{array}$ & $k_{1}\left(\min ^{-1}\right)$ & $\underset{\left(\mathrm{mg} \mathrm{g}^{-1}\right)}{\mathrm{q}_{\mathrm{e}(\mathrm{cal})}}{ }^{\mathrm{b}}$ & $\mathbf{r}^{2}$ & $\begin{array}{c}\mathrm{k}_{2} \times 10^{4} \\
\left(\mathrm{~g} \mathrm{mg}^{-1} \min ^{-1}\right)\end{array}$ & $\underset{\left(\mathrm{mg} \mathrm{g}^{-1}\right)}{\mathrm{qe}_{\text {cal }}{ }^{\mathrm{b}}}$ & $\mathrm{r}^{2}$ \\
\hline 665 & 77 & 0.0118 & 52.83 & 0.9405 & 10.6 & 84.75 & 0.9977 \\
\hline
\end{tabular}

\subsubsection{Adsorption Isotherms}

The sorption studies were investigated at different temperatures $(298,308$, and $318 \mathrm{~K})$. The removal of $\mathrm{Cd}(\mathrm{II})$ by the 1,2,3,4-tetrahydropyrimidine derivative (4) at three different temperatures is illustrated in the Langmuir and Freundlich linear equations, as shown in Figure 6. The Langmuir and Freundlich coefficients $\left(Q_{0}, \mathrm{~b}, k, \mathrm{n}, r^{2}\right.$ and $\left.R_{L}\right)$ are listed in Table 2. With respect to the values of $Q_{0}$ and $k$, the effectiveness of the 1,2,3,4-tetrahydropyrimidine derivative (4) for the uptake of Cd(II) increases with increase in temperature (Table 2). It is well known that the act of increasing the temperature increases the diffusion rate of the metal ion through the outer boundary layer and into the internal pores of the adsorbent molecules, which eventually decreases the viscosity of the solution.

Given the correlation coefficients in Table 2, the experimental details better adjusted the Langmuir isotherm than the Freundlich isotherm for the adsorption of the $\mathrm{Cd}(\mathrm{II})$ ions. Therefore, the adsorption of $\mathrm{Cd}$ (II) ions by the 1,2,3,4-tetrahydropyrimidine derivative (4) shows the formation of a monolayer coverage of the metallic ion of cadmium with a maximum capacity of $151.16 \mathrm{mg} \mathrm{g}^{-1}$. Reed and Matsumoto [38] investigated the removal of cadmium by a commercial activated carbon and indicated that a greater difference between $n$ and 1 corresponds to a vast distribution of the surface bond energies. Therefore, the 1,2,3,4-tetrahydropyrimidine derivative (4) shows a large Cd(II)-surface bond energy distribution as the temperature increases. 

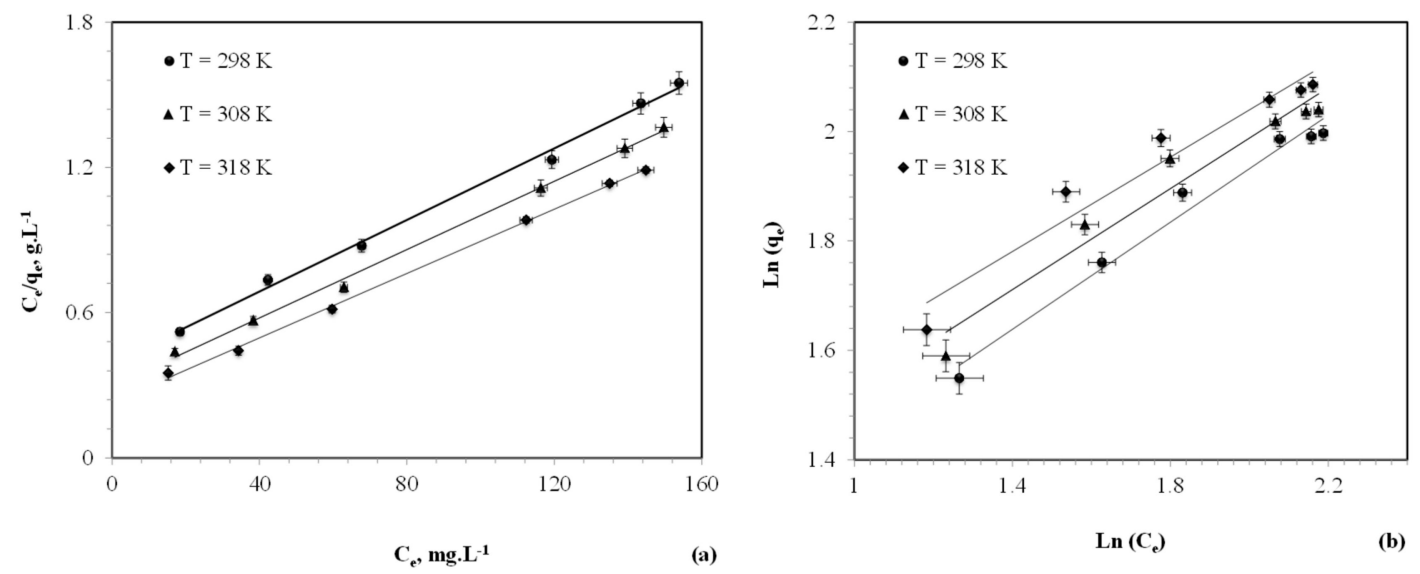

Figure 6. (a) Langmuir and (b) Freundlich equilibrium sorption isotherms for Cd(II) onto 1,2,3,4tetrahydropyrimidine at different temperatures, $\mathrm{pH}=7 \pm 0.2$.

Table 2. Effect of temperature on the values of Langmuir and Freundlich isotherm constants.

\begin{tabular}{cccccccc}
\hline \multirow{2}{*}{$\begin{array}{c}\text { Temperature } \\
(\mathbf{K})\end{array}$} & \multicolumn{3}{c}{ Langmuir Constants } & \multicolumn{4}{c}{ Freundlich Constants } \\
\cline { 2 - 8 } & $\boldsymbol{Q}_{\mathbf{0}} \mathbf{( m g ~ g ~}^{\mathbf{- 1}} \mathbf{)}$ & $\left.\boldsymbol{b} \mathbf{( L ~ m g ~}^{-\mathbf{1}}\right)$ & $\boldsymbol{r}^{\mathbf{2}}$ & $\boldsymbol{R}_{\boldsymbol{L}}$ & $\boldsymbol{n}$ & $\boldsymbol{k}$ & $\boldsymbol{r}^{\mathbf{2}}$ \\
\hline 298 & 135.14 & 0.01896 & 0.9959 & 0.0815 & 2.044 & 8.98 & 0.9781 \\
308 & 140.85 & 0.02404 & 0.9967 & 0.0679 & 2.164 & 11.58 & 0.9529 \\
318 & 151.16 & 0.02959 & 0.9986 & 0.0521 & 2.316 & 14.99 & 0.9462 \\
\hline
\end{tabular}

\subsubsection{Thermodynamic Study}

The results of the obtained thermodynamic parameters are illustrated in Table 3. The enthalpy $\left(\Delta \mathrm{H}^{\mathrm{o}}\right)$ value calculated from the graph of $\operatorname{Ln}(\mathrm{ka})$ versus $\mathrm{T}^{-1}$ of Figure 7 exhibits the endothermic kind of the adsorption operation of $\mathrm{Cd}(\mathrm{II})$ ions, whereas the positive valor of $\Delta \mathrm{S}^{0}$ denotes the increased randomness at the 1,2,3,4-tetrahydropyrimidine derivative (4) solution interface. These obtained results are coherent with those reported by Mohaptra and Anand [39] and Mohaptra et al. [40]. The negative value of the free energy change $\Delta G^{0}$ supports the spontaneous nature of the adsorption, which is proven by the $R_{L}$ value, and found to be less than unity. It should be noted that the value of $\Delta G^{0}$ decreases when the temperature increases from 298 to $318 \mathrm{~K}$, indicating that better adsorption is obtained at higher temperatures.

Table 3. Thermodynamic parameters for $\mathrm{Cd}(\mathrm{II})$ adsorption at $\mathrm{pH}=7$.

\begin{tabular}{|c|c|c|c|c|c|}
\hline Temperature (K) & $K a$ & $\Delta \mathrm{G}^{0}\left(\mathrm{~kJ} \mathrm{~mol}{ }^{-1}\right)$ & $\Delta \mathrm{S}^{0}\left(\mathrm{~kJ} \mathrm{~mol}^{-1} \mathrm{~K}^{-1}\right)$ & $\Delta \mathrm{H}^{0}\left(\mathrm{~kJ} \mathrm{~mol}^{-1}\right)$ & $r^{2}$ \\
\hline 298 & 2.562 & -2.332 & 0.0818 & & \\
\hline 308 & 3.387 & -3.125 & 0.0818 & 22.07 & 0.9996 \\
\hline 318 & 4.485 & -3.970 & 0.0818 & & \\
\hline
\end{tabular}




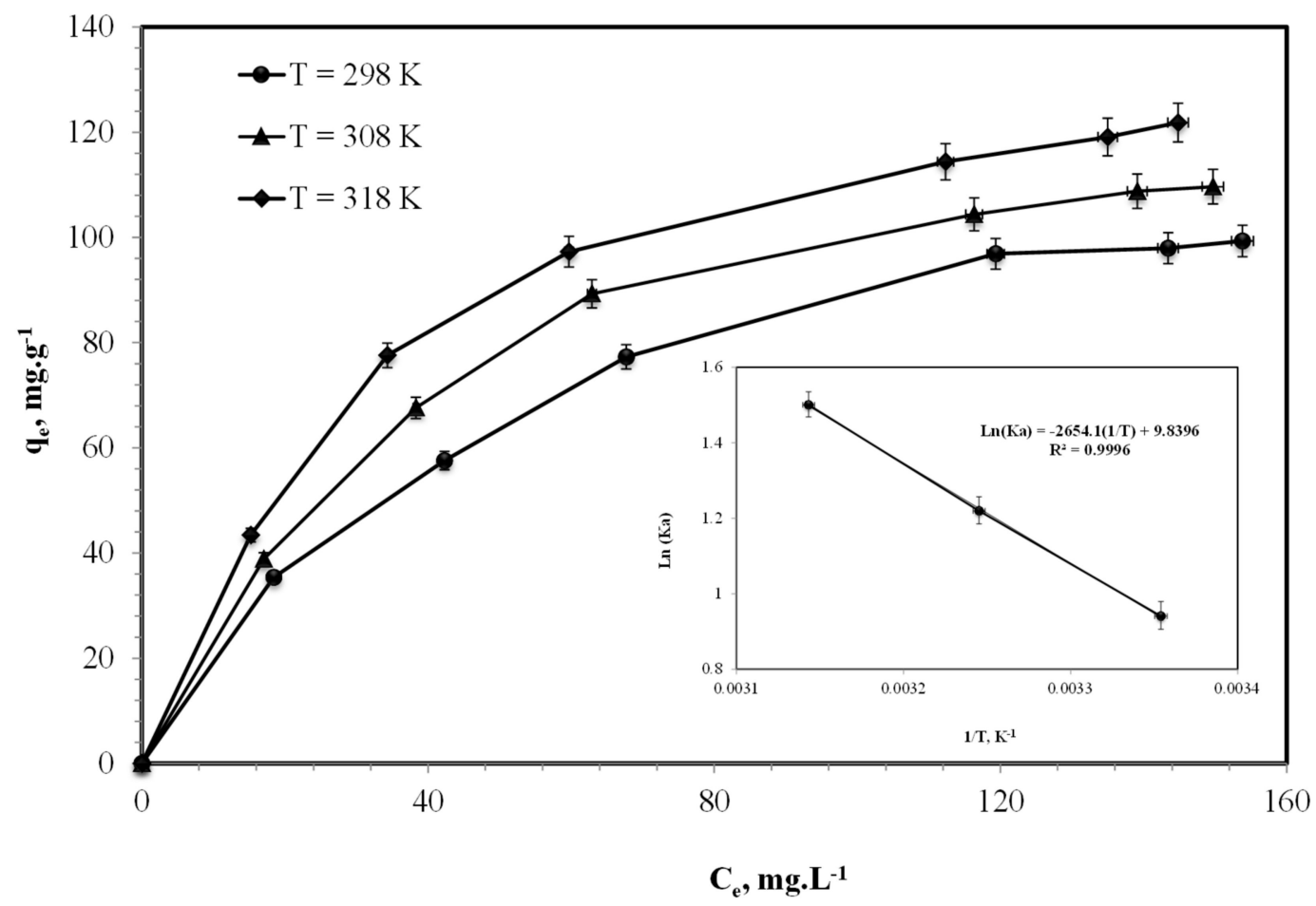

Figure 7. Langmuir isotherms for adsorption of $\mathrm{Cd}(\mathrm{II})$ onto 1,2,3,4-tetrahydropyrimidine at different temperatures and $\mathrm{pH}$. The embedded figure is the plot of $\operatorname{Ln} K_{a}$ against reciprocal temperature.

\subsection{Mechanism of Adsorption}

The uptake of cadmium ions can be controlled either by mass transfer in the liquid boundary film or by intra-particular mass transfer. The external mass transfer coefficient, $\beta_{\mathrm{L}}\left(\mathrm{m} \mathrm{s}^{-1}\right)$ of $\mathrm{Cd}(\mathrm{II})$ in the boundary film, can be evaluated using the formula [41,42]:

$$
\ln \left(\frac{C_{t}}{C_{0}}-\frac{1}{1+m \cdot K_{a}}\right)=\ln \left(\frac{m \cdot K_{a}}{1+m \cdot K_{a}}\right)-\left(\frac{1+m \cdot K_{a}}{m \cdot K_{a}}\right) \cdot \beta_{L} \cdot S_{S} \cdot t,
$$

where $C_{\mathrm{t}}$ and $C_{0}$ (both in $\mathrm{mg} \mathrm{L}^{-1}$ ) are the respective concentrations of the metal ions at time $t$ and zero, $K_{a}\left(\mathrm{~L} \mathrm{~g}^{-1}\right)$ is a constant defined as the product of the Langmuir constants: $K_{a}=Q_{0} \cdot \mathrm{b} ; m(\mathrm{~g})$ is the adsorbent mass, and $S_{S}$ is the adsorbent surface area $\left(\mathrm{m}^{2} \mathrm{~g}^{-1}\right)$. A straight line in $\ln \left[\left(C_{\mathrm{t}} / C_{0}-1 /(1+m\right.\right.$ $\left.K_{a}\right)$ ] versus $t$ plot is required to prove the reliability of the model.

The adsorbed species can also be transported from the solution to the solid phase across the intra-particle diffusion/transport procedure. The intra-particular diffusion is the limiting step in many adsorption procedures. The possibility of intra-particular diffusion was explored by the diffusion mode of Weber and Morris [43,44].

$$
q_{t}=k_{d i f} \cdot t^{1 / 2}+C,
$$

where $C$ is the intercept and $k_{d i f}$ is the intra-particle diffusion rate constant. The $k_{d i f}$ values for the tested adsorbent are calculated through the slopes of the plots (Figure 7) and described in Table 4. The validity of these models is afterward discussed.

The model of mass transfer rate based on a linear relationship between $\ln \left[\left(C_{t} / C_{0}-1 /\left(1+m k_{a}\right)\right]\right.$ and $t$ did not provide a linear plot, demonstrating the invalidity of this model. The value of the regression coefficient is calculated from Equation (10) for the 1,2,3,4-tetrahydropyrimidine derivative (4). This means that the uptake of cadmium ions at the tested adsorbent sites is not controlled by the liquid phase mass transfer rate.

Conversely, the uptake of $\mathrm{Cd}(\mathrm{II})$ on the surface of the adsorbent may be controlled by the intra-particle diffusion kinetic model, since the values of qt are found to be linearly correlated with $\mathrm{t}^{1 / 2}$ 
values. Besides, the regression coefficient values are equal to 0.98 , indicating the applicability of this model. The intra-particle diffusion plots are shown in Figure 8. The main parameters of this model are determined and compiled in Table 4. The intercept values (i.e., C, Table 4) give an idea about the boundary layer thickness. The larger the intercept, the larger the boundary layer effect is.

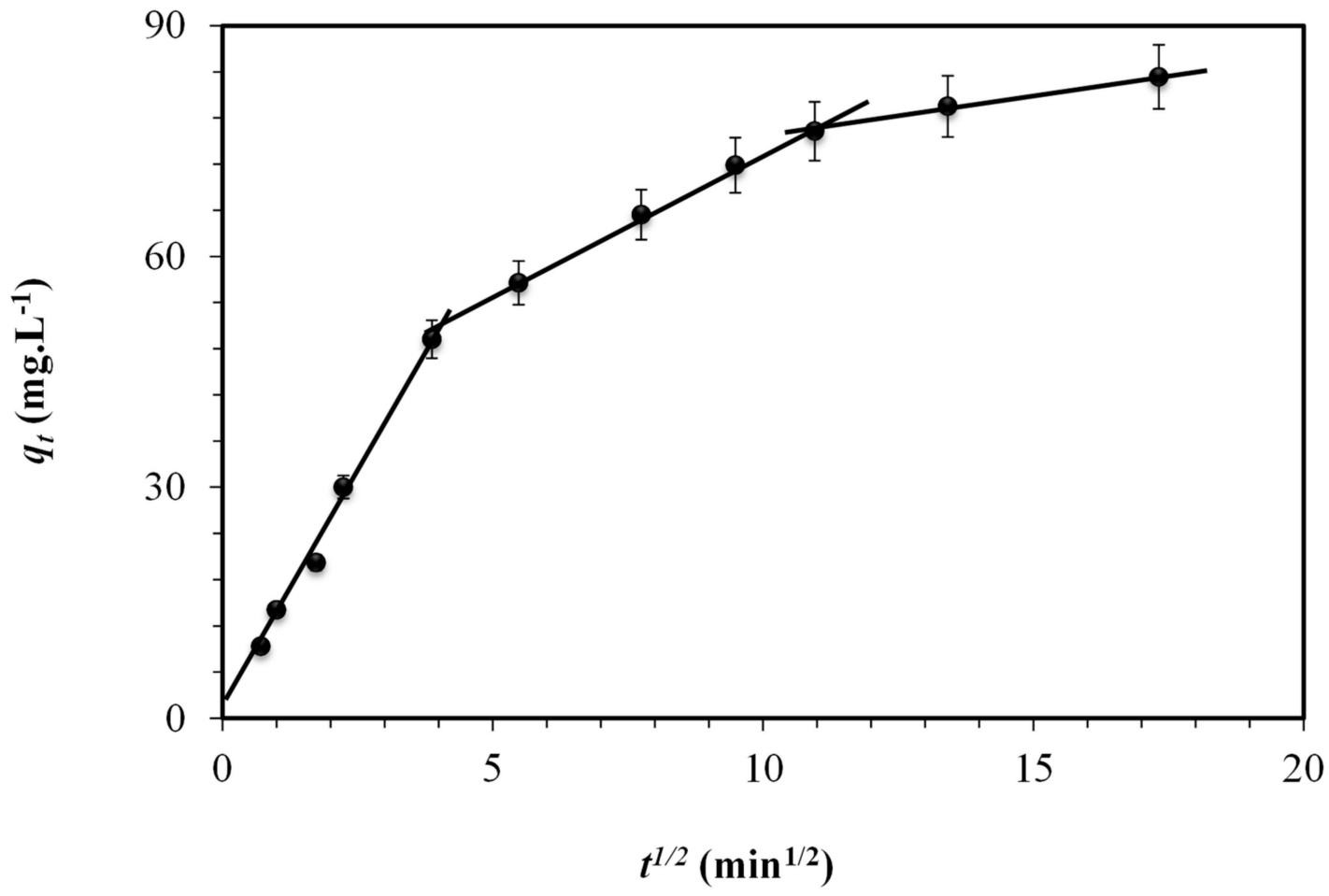

Figure 8. $q_{t}$ versus $\mathrm{t}^{1 / 2}$ plot for the intraparticle diffusion.

The intra-particle diffusion plot of $q_{t}$ versus $\mathrm{t}^{1 / 2}$ (Figure 8) shows a two-stage sorption, i.e., multi-linear [45]. The first is a sharp stage, which may have produced from the diffusion of Cd(II) through the solution to the external surface of the adsorbent and then to the surface through the boundary layer. Meantime, the second step may indicate the final equilibrium whereabouts the intra-particle diffusion begins to decelerate as a result of the lower concentration gradient of Cd(II) ions.

From the tabulated results (Table 4), it can be seen that the diffusion rate has decreased with increasing contact time due to the smaller pores accessible for diffusion, since the Cd(II) ions are formerly diffused into the internal structure of the adsorbent in the first step. This is evidenced by the smaller value of the rate parameters $k_{d i f 1}$ as compared to $k_{d i f 2}$. Additionally, the constant related to the boundary layer ply $(C)$ is larger in the second step, indicating a greater boundary layer effect [46].

Table 4. Kinetic parameters for the Cd(II) ions adsorption onto 1,2,3,4-tetrahydropyrimidine based on the intraparticle diffusion model.

\begin{tabular}{|c|c|c|c|c|c|c|c|c|}
\hline \multicolumn{9}{|c|}{ Intraparticle Diffusion Equation Parameters } \\
\hline $\begin{array}{c}k_{d i f 1} \\
\mathrm{mg} / \mathrm{g} \min ^{1 / 2}\end{array}$ & $C$ & $r^{2}$ & $\begin{array}{c}k_{\text {dif } 2} \\
\mathrm{mg} / \mathrm{g} \min ^{1 / 2}\end{array}$ & C & $r^{2}$ & $\begin{array}{c}k_{\text {dif } 2} \\
\mathrm{mg} / \mathrm{g} \min ^{1 / 2}\end{array}$ & C & $r^{2}$ \\
\hline 12.58 & 0.56 & 0.9928 & 3.83 & 35.15 & 0.9960 & 1.1 & 64.45 & 0.9934 \\
\hline
\end{tabular}

\subsection{Comparison of Cd(II) Adsorption Capacity with Other Previously Reported Adsorbents}

Table 5 summarizes the adsorption capacity of $\mathrm{Cd}(\mathrm{II})$ ions by the 1,2,3,4-tetrahydropyrimidine derivative (4) and other alternative adsorbents as reported in the literature. The 1,2,3,4-tetrahydropyrimidine 
derivative (4) described in this work presents a better adsorption performance and shows a higher adsorption capacity for Cd(II) than other adsorbents reported in the literature.

Table 5. Comparison of 1,2,3,4-tetrahydropyrimidine adsorption capacity with some adsorbents for cadmium (II).

\begin{tabular}{cccc}
\hline Adsorbent & $\boldsymbol{q}_{\boldsymbol{e}}\left(\mathbf{m g ~ g}^{\mathbf{- 1}}\right)$ & Temp. (K) & Ref. \\
\hline C,N-pyridylpyrazole & 4.8 & 298 & {$[47]$} \\
Gallic acid & 6.09 & 298 & {$[48]$} \\
3-Aminopropytriethoxysilane & 14.1 & 323 & {$[49]$} \\
Chitosan/cotton fibers & 15.74 & 298 & {$[50]$} \\
Melamine-based NH Nendrimer $_{\text {den }}$ & 71.1 & 323 & {$[49]$} \\
Spirodela polyrhiza & 36 & 298 & {$[51]$} \\
Pyrazol-3-ylimine & 74.89 & 298 & {$[52]$} \\
CMJFMH & 88 & 298 & {$[53]$} \\
PEI/SA-MCCMV & 139.47 & 298 & {$[36]$} \\
Present Work & 135.14 & 298 & - \\
Present Work & 151.16 & 318 & - \\
\hline
\end{tabular}

\section{Conclusions}

This research work presented the 1,2,3,4-tetrahydropyrimidine derivative as an effective and rapid absorption of $\mathrm{Cd}(\mathrm{II})$ ions from aqueous solutions. The equilibrium data were fitted to the Freundlich and Langmuir isothermal models. At a pH value of 6-7 at $328 \mathrm{~K}$, an adsorption capacity of cadmium ions of approximately $151.16 \mathrm{mg} \mathrm{g}^{-1}$ was obtained. Both $\mathrm{pH}$ and temperature are critical parameters for the extension of $\mathrm{Cd}$ (II) uptake. Furthermore, the suitability of the kinetic models for the adsorption of $\mathrm{Cd}$ (II) ions on the 1,2,3,4-tetrahydropyrimidine derivative was also discussed. The kinetic measurement of the adsorption process of $\mathrm{Cd}$ (II) ions is considered to follow a pseudo-second-order rate law. The evaluated thermodynamic parameters indicate that the adsorption process of $\mathrm{Cd}$ (II) ions on the milled goethite is spontaneous and endothermic.

Author Contributions: Formal analysis, L.K.; Investigation, M.O.M.

Acknowledgments: The authors gratefully acknowledge the Deanship of Academic Research at Imam Mohammad Ibn Saud Islamic University (IMSIU), Riyadh, Kingdom of Saudi Arabia, for funding this work through research project Number 371222, $1438 \mathrm{H}$.

Conflicts of Interest: We have no conflict of interest to declare.

\section{References}

1. Bailey, S.E.; Olin, T.J.; Bricka, R.M.; Adrian, D.D. A review of potentially low-cost sorbents for heavy metals. Water Res. 1999, 33, 2469-2479. [CrossRef]

2. Bode-Aluko, C.A.; Pereao, O.; Ndayambje, G.; Petrik, L. Adsorption of toxic metals on modified polyacrylonitrile nanofibres: A review. Water Air Soil Poll. 2017, 228, 35. [CrossRef]

3. Uzun, I.; Güzel, F. Adsorption of some heavy metal ions from aqueous solution by activated carbon and comparison of percent adsorption results of activated carbon with those of some other adsorbents. Turk. J. Chem. 2000, 24, 291-297.

4. Gier, S.; Johns, W.D. Heavy metal-adsorption on micas and clay minerals studied by X-ray photoelectron spectroscopy. Appl. Clay Sci. 2000, 16, 289-299. [CrossRef]

5. Koppelman, M.H.; Dillard, J.G. A study of the adsorption of $\mathrm{Ni}(\mathrm{II})$ and $\mathrm{Cu}(\mathrm{II})$ by clay minerals. Clays Clay Miner. 1977, 25, 457-462. [CrossRef]

6. Biskup, B.; Subotic, B. Kinetic analysis of the exchange processes between sodium ions from zeolite A and cadmium, copper and nickel ions from solutions. Sep. Purif. Technol. 2004, 37, 17-31. [CrossRef]

7. Cincotti, A.; Mameli, A.; Locci, A.M.; Orru, R.; Cao, G. Heavy metals uptake by Sardinian natural zeolites: Experiment and modeling. Ind. Eng. Chem. Res. 2006, 45, 1074-1084. [CrossRef] 
8. Araki, S.; Li, T.; Li, K.; Yamamoto, H. Preparation of zeolite hollow fibers for high-efficiency cadmium removal from waste water. Sep. Purif. Technol. 2019, 221, 393-398. [CrossRef]

9. O'Connell, D.W.; Birkinshaw, C.; O'Dwyer, T.F. Heavy metal adsorbents prepared from the modification of cellulose: A review. Bioresour. Technol. 2008, 99, 6709-6724. [CrossRef]

10. Dang, V.B.H.; Doan, H.D.; Dang-Vuc, T.; Lohi, A. Equilibrium and kinetics of biosorption of cadmium(II) and copper(II) ions by wheat straw. Bioresour. Technol. 2009, 100, 211-219. [CrossRef]

11. Zewail, T.M.; El-Garf, S.A.M. Preparation of agriculture residue based adsorbents for heavy metal removal. Desalin. Water Treat. 2010, 22, 363-370. [CrossRef]

12. Mo, J.; Yang, Q.; Zhang, N.; Zhang, W.; Zheng, Y.; Zhang, Z. A review on agro-industrial waste (AIW) derived adsorbents for water and wastewater treatment. J. Environ. Manag. 2018, 227, 395-405. [CrossRef] [PubMed]

13. Wang, L.; Wu, X.L.; Xu, W.H.; Huang, X.J.; Liu, J.H.; Xu, A.W. Stable organic-inorganic hybrid of polyaniline $/ \alpha$-zirconium phosphate for efficient removal of organic pollutants in water environment. Appl. Mater. Interfaces 2012, 4, 2686-2692. [CrossRef] [PubMed]

14. Gao, B.; Gao, Y.; Li, Y. Preparation and chelation adsorption property of composite chelating material poly(amidoxime) $/ \mathrm{SiO}_{2}$ towards heavy metal ions. Chem. Eng. J. 2010, 158, 542-549. [CrossRef]

15. Zaitseva, N.; Zaitsev, V.; Walcarius, A. Chromium(VI) removal via reduction-sorption on bi-functional silica adsorbents. J. Hazard. Mater. 2013, 250-251, 454-461. [CrossRef] [PubMed]

16. Simsek, E.B.; Duranoglu, D.; Beker, U. Heavy metal adsorption by magnetic hybrid-sorbent: An experimental and theoretical approach. Sep. Sci. Technol. 2012, 47, 1334-1340. [CrossRef]

17. Suchithra, P.S.; Vazhayal, L.; Mohamed, A.P.; Ananthakumar, S. Mesoporous organic-inorganic hybrid aerogels through ultrasonic assisted sol-gel intercalation of silica-PEG in bentonite for effective removal of dyes, volatile organic pollutants and petroleum products from aqueous solution. Chem. Eng. J. 2012, 200-202, 589-600. [CrossRef]

18. Repo, E.; Warchoł, J.K.; Bhatnagar, A.; Sillanpää, M. Heavy metals adsorption by novel EDTA-modified chitosan-silica hybrid materials. J. Colloid Interface Sci. 2011, 358, 261-267. [CrossRef] [PubMed]

19. Ge, P.; Li, F.; Zhang, B. Synthesis of modified mesoporous materials and comparative studies of removal of heavy metal from aqueous solutions. Pol. J. Environ. Stud. 2010, 19, 301-308.

20. Pang, Y.; Zeng, G.; Tang, L.; Zhang, Y.; Liu, Y.; Lei, X.; Li, Z.; Zhang, J.; Xie, G. PEI-grafted magnetic porous powder for highly effective adsorption of heavy metal ions. Desalination 2011, 281, 278-284. [CrossRef]

21. Wang, L.; Zhang, J.; Wang, A. Fast removal of methylene blue from aqueous solution by adsorption onto chitosan-g-poly (acrylic acid)/attapulgite composite. Desalination 2011, 266, 33-39. [CrossRef]

22. Radi, S.; Toubi, Y.; Tighadouini, S.; Baquet, M. Solid-phase extraction of $\mathrm{Hg}(\mathrm{II}), \mathrm{Zn}$ (II) and Cd(II) from water using silica gel modified with bipyrazolic tripodal receptor. Ind. J. Chem. Technol. 2013, 20, 423-428.

23. Radi, S.; Basbas, N.; Tighadouini, S.; Bacquet, M.; Degoutin, S.; Cazier, F. New amine-modified silica: Synthesis, characterisation and its use in the $\mathrm{Cu}(\mathrm{II})$-Removal from aqueous solutions. Prog. Nanotechnol. Nanomater. 2013, 2, 108-116. [CrossRef]

24. Radi, S.; Toubi, T.; Bacquet, M.; Degoutin, S.; Cazier, F. 1-(Pyridin-2-yl) Imine functionalized silica gel: Synthesis, Characterization and preliminary use in metal ion extraction. Sep. Sci. Technol. 2013, 48, 1349-1355. [CrossRef]

25. Radi, S.; Toubi, Y.; Bacquet, M. Synthesis of pyridin-3-yl-functionalized silica as a chelating sorbent for solid-phase adsorption of $\mathrm{Hg}(\mathrm{II}), \mathrm{Pb}(\mathrm{II}), \mathrm{Zn}(\mathrm{II})$ and $\mathrm{Cd}(\mathrm{II})$ from water. Chem. Res. Intermed. 2013, 39, 3791-3802.

26. Shami, R.B.; Shojaei, V.; Khoshdast, H. Efficient cadmium removal from aqueous solutions using a sample coal waste activated by rhamnolipid biosurfactant. J. Environ. Manag. 2019, 231, 1182-1192. [CrossRef]

27. Dzhodzhyk, O.; Kolesnyk, I.; Konovalova, V.; Burban, A. Modified polyethersulfone membranes with photocatalytic properties. Chem. Chem. Technol. 2017, 11, 277-284. [CrossRef]

28. Mercier, L.; Pinnavaia, T.J. Heavy metal ion adsorbents formed by the grafting of a thiol functionality to mesoporous silica molecular sieves: Factors affecting $\mathrm{Hg}(\mathrm{II})$ uptake. Environ. Sci. Technol. 1998, 32, 2749-2754. [CrossRef]

29. Ould M'hamed, M.; Alshammari, A.G.; Lemine, O.M. Green High-Yielding One-Pot Approach to Biginelli Reaction under Catalyst-Free and Solvent-Free Ball Milling Conditions. Appl. Sci. 2017, 6, 431. [CrossRef] 
30. Khezami, L.; Ould M'hamed, M.; Lemine, O.M.; Bououdina, M.; Bessadok-Jemai, A. Milled goethite nanocrystallinefor selective and fast uptake of cadmium ions from aqueous solution. Desalin. Water Treat. 2016, 57, 6531-6539. [CrossRef]

31. Huang, C.P.; Smith, E.H. Removal of cadmium(II) from plating wastewater by activated carbon process. In Chemistry in Water Reuse; Cooper, W., Ed.; Ann Arbor Science: Ann Arbor, MI, USA, 1981; pp. 355-412.

32. Gupta, V.K.; Sharma, S.; Yadau, I.S.; Dinesh, M. Utilisation of bagasses fly ash generated in the sugar industry for the removal of phenol and p-nitrophenol from waste water. J. Chem. Technol. Biot. 1998, 71, 180-186. [CrossRef]

33. Benjamin, M.M. Effects of Competing Metals and Complexing Ligands on Trace Metal Adsorption at the Oxide/Solution Interface. PhD Thesis, Stanford University, Stanford, CA, USA, 1978.

34. Haghesresht, F.; Lu, G. Adsorption characteristics of phenolic compounds onto coal-reject-derived adsorbents. Energy Fuels. 1998, 12, 1100-1107. [CrossRef]

35. Hana, R.; Li, H.; Li, Y.; Zhang, J.; Xiao, H.; Shi, J. Biosorption of copper and lead ions by waste beer yeast. J. Hazard. Mater. 2006, B137, 1569-1576. [CrossRef] [PubMed]

36. Zhang, C.; Su, J.; Zhu, H.; Xiong, J.; Liu, X.; Li, D.; Chen, Y.; Li, Y. The removal of heavy metal ions from aqueous solutions by amine functionalized cellulose pretreated with microwave- $\mathrm{H}_{2} \mathrm{O}_{2}$. RSC Adv. 2017, 7, 34182. [CrossRef]

37. Tobin, J.M.; Cooper, D.G.; Neufeld, R.J. Uptake of metal ions by Rhizopus arrhizus biomass. Appl. Environ. Microb. 1984, 47, 821-824.

38. Reed, B.E.; Matsumoto, M.R. Modeling cadmium adsorption in single and binary adsorbent (powdered activated carbon) systems. J. Environ. Eng. 1993, 119, 332-348. [CrossRef]

39. Mohapatra, M.; Anand, S. Cd(II) adsorption on synthetic goethite: Kinetics and thermodynamics aspects. Indian J. Environ. Prot. 2006, 26, 1057-1066.

40. Mohapatra, M.; Mohapatra, L.; Singh, P.; Anand, S.; Mishra, B.K. A comparative study on Pb(II), Cd(II), $\mathrm{Cu}(\mathrm{II}), \mathrm{Co}(\mathrm{II})$ adsorption from single and binary aqueous solutions on additive assisted nano-structured goethite. Int. J. Eng. Sci. Technol. 2010, 2, 89-103. [CrossRef]

41. Vinod, V.P.; Anirudhan, T.S. Adsorption Behaviour of Basic Dyes on the Humic Acid Immobilized Pillared Clay. Water Air Soil Pollut. 2003, 150, 193-217. [CrossRef]

42. Sahmoune, M.N.; Ouazene, N. Mass-transfer processes in the adsorption of cationic dye by sawdust. Environ. Prog. Sustain. Energ. 2012, 31, 597-603. [CrossRef]

43. Hameed, B.H.; Salman, J.M.; Ahmad, A.L. Adsorption isotherm and kinetic modeling of 2, 4-D pesticide on activated carbon derived from date stones. J. Hazard. Mater. 2009, 163, 121-126. [CrossRef] [PubMed]

44. El-Sikaily, A.; El Nemr, A.; Khaled, A.; Abdelwehab, O. Removal of toxic chromium from wastewater using green alga Ulva lactuca and its activated carbon. J. Hazard. Mater. 2007, 148, 216-228. [CrossRef]

45. Yazdani, M.; Tuutijärvi, T.; Bhatnagar, A.; Vahala, R. Adsorptive removal of arsenic (V) from aqueous phase by feldspars: Kinetics, mechanism, and thermodynamic aspects of adsorption. J. Mol. Liq. 2016, 214, 149-156. [CrossRef]

46. Milosavljevic, N.B.; Ristic, M.; Peric-Grujic, A.A.; Filipovic, J.M.; Strbac, S.B.; Rakocevic, Z.L.; Krusic, M.T.K. Removal of $\mathrm{Cu}^{2+}$ ions using hydrogels of chitosan, itaconic and methacrylic acid: FTIR, SEM/EDX, AFM, kinetic and equilibrium study. Colloids and Surfaces A: Physicochem. Eng. Aspects 2011, 388, 59-69. [CrossRef]

47. Radi, S.; Ramdani, A.; Lekchiri, Y.; Morcellet, M.; Crini, G.; Janus, L.; Bacquet, M. Immobilization of pyrazole compounds on silica gels and their preliminary use in metal ion extraction. New J. Chem. 2003, 27, 1224-1227. [CrossRef]

48. Xie, F.; Lin, X.; Wu, X.; Xie, Z. Solid phase extraction of lead (II), copper (II), cadmium (II), and nickel (II) using gallic acid modified silica gel prior to determination by flame atomic adsorption spectrometry. Talanta 2008, 74, 836-843. [CrossRef]

49. Shahbazi, A.; Younesi, H.; Badiei, A. Functionalized SBA-15 mesoporous silica by melamine-based dendrimer amines for adsorptive characteristics of $\mathrm{Pb}(\mathrm{II}), \mathrm{Cu}(\mathrm{II})$ and $\mathrm{Cd}(\mathrm{II})$ heavy metal ions in batch and fixed bed column. Chem. Eng. J. 2011, 168, 505-518. [CrossRef]

50. Zhang, G.; Qu, R.; Sun, C.; Ji, C.; Hou, C.; Wang, C.; Niu, Y.J. Adsorption for metal ions of chitosan coated cotton fiber. Appl. Polym. Sci. 2008, 110, 2321-2327. 
51. Meitei, M.D.; Prasad, M.N.V. Lead (II) and cadmium (II) biosorption on Spirodela polyrhiza (L.) Schleiden biomass. J. Environ. Chem. Eng. 2013, 1, 200-207. [CrossRef]

52. Radi, S.; Tighadouini, S.; Bacquet, M.; Degoutin, S.; Cazier, F.; Zaghrioui, M.; Mabkhot, Y.N. Organically Modified Silica with Pyrazole-3-carbaldehyde as a New Sorbent for Solid-Liquid Extraction of Heavy Metals. Molecules 2014, 19, 247-262. [CrossRef]

53. Du, Z.; Zheng, T.; Wang, P.; Hao, L.; Wang, Y. Fast microwave-assisted preparation of a low-cost and recyclable carboxyl modified lignocellulose-biomass jute fiber for enhanced heavy metal removal from water. Bioresour. Technol. 2016, 201, 41-49. article distributed under the terms and conditions of the Creative Commons Attribution (CC BY) license (http://creativecommons.org/licenses/by/4.0/). 